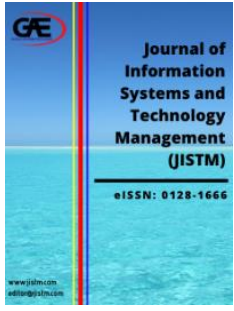

\author{
JOURNAL OF INFORMATION \\ SYSTEM AND TECHNOLOGY \\ MANAGEMENT (JISTM) \\ WWw.jistm.com
}

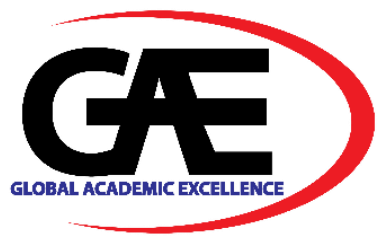

\title{
BUILDING INFORMATION MODELING (BIM) AND GEOGRAPHIC INFORMATION SYSTEM (GIS) DATA COMPATIBILITY FOR CONSTRCUTION PROJECT
}

\author{
Wan Nor Fa'aizah Wan Abdul Basir ${ }^{*}$, Uznir Ujang ${ }^{2}$, Zulkepli Majid ${ }^{3}$ \\ 1 Faculty of Built Environment and Surveying, Universiti Teknologi Malaysia, Malaysia \\ Email:wnfaaizah2@live.utm.my \\ 2 Faculty of Built Environment and Surveying, Universiti Teknologi Malaysia, Malaysia \\ Email: mduznir@utm.my \\ 3 Faculty of Built Environment and Surveying, Universiti Teknologi Malaysia, Malaysia \\ Email: zulkeplimajid@utm.my \\ * $\quad$ Corresponding Author
}

\section{Article Info:}

Article history:

Received date: 01.10 .2021

Revised date: 01.11.2021

Accepted date: 20.11.2021

Published date: 01.12.2021

\section{To cite this document:}

Basir, W. N. F. W. A., Ujang, U., \& Majid, Z. (2021). Building Information Modeling (BIM) And Geographic Information System (GIS) Data Compatibility For Construction Project. Journal of Information System and Technology Management, 6 (24), 278-289.

DOI: $10.35631 /$ JISTM.624026

This work is licensed under CC BY 4.0 (c) 2
Abstract:

Building Information Modeling (BIM) is a technology that focusing on the building element properties to the construction components which cover the interior and exterior building, while Geographic Information System (GIS) describe to the technology that can provide the large-scale information which cover inside and outside buildings (spaces and areas). In construction project application, BIM technology already been used as a worldwide tool while GIS rarely been applied. Each technology contains their own advantages that can be utilized in the construction project application. To bring the best effective approach in construction project, the integration between BIM and GIS technology can be considered. This paper presented an attempt in integrating BIM and GIS by using FME as a data integration platform to solve the limitation of BIM in construction project by using advantages of GIS. Through this research, an investigation of the data exchange during integration process between BIM and GIS will be look up. By using this approach, it is possible to store the BIM and GIS data in one environment. The end results for this paper will cover the method of the data exchange between BIM to GIS and GIS to BIM. Besides that, this paper highlight how GIS can solve the limitation in $\mathrm{BIM}$ in construction project.

Keywords:

Building Information System, Geographic Information System, Data Compatibility, Data Exchange 


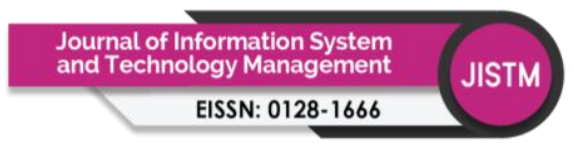

Volume 6 Issue 24 (December 2021) PP. 278-289 DOI: 10.35631/JISTM.624026

\section{Introduction}

Building information modelling (BIM) introduces explanation of a construction project in specifics geometrical and attribute features, and Geographic Information System (GIS) is the highly crucial instrument to explain a digital city in multi-rate, multi-scale, and space-time dimensions (Yuan and Shen, 2010). For construction project, BIM have been offered numerous improvements in term of design, planning, and implementation, but there are several restrictions which can be detected. For examples site selection, monitoring delivering goods, planning for emergency, monitoring utilities, etc. This restriction can be resolved by including the GIS application since GIS can offer spatial analysis that needed the real environment of the construction site and building itself. In the application of integration BIM and GIS, improvements of BIM and GIS domains can be used, and geospatial information can support building geometries and properties to provide a whole description of the complete construction environment. Numerous attempts were made in integration of BIM-GIS. For examples, Irizarry and Karan (2013) produced a unified GIS-BIM prototype to enhance the visual surveillance of management the construction supply chain. Kim et al. (2012) established a web-based platform with Google Earth and Google Map plugins to observe and imagine the energy use for Smart Green City development. Berlo and Latt (2010) encouraged those numerous experiments appear emphasis on whichever BIM or GIS, for example concerning the buildings as data in geospatial perspective. But, because BIM and GIS apply different technologies, standards and syntax explanations, suitable methods for data exchange are needed. Different methods exist for sharing information such as Industry Foundation Classes (IFC) offered by buildingSMART, Construction Operations Building information exchange (COBie), and Geographic Markup Language (GML) established via Open Geospatial Consortium (OGC). In this study, Revit Architecture was chosen to develop BIM model while ArcGIS software for GIS application, and FME is used as a data integration platform.

\section{Building Information Modelling and Geographic Information System in Construction}

\section{Building Information Modelling (BIM)}

BIM may be described in various conditions from model and design data to construction management. In term of three-dimensional (3D) viewpoint, BIM can explain as a theoretical method to the building design and construction that contains 3D parametric modeling of building for design and detailing and computer-intelligible exchange of building information between design, construction, and other disciplines (Sacks, et al., 2010; Kocakaya, et al., 2019). As of project data management and design perspective, BIM is a set of networking strategies, methods and tools that can designed an approach to achieve building design and project information in digital format throughout all life-cycle phases (Penttilä, 2006). In term of construction management, BIM is a smart replication of architecture to accomplish a unified project delivery (Eastman et al., 2008).

The National Building Information Model Standard (NBIMS) describes BIM as "digital representation of physical and functional characteristics of a facility and it serves as a shared knowledge resource for information about a facility forming a reliable basis for decisions during its life cycle from inception onward" (Kubba, 2012). BIM symbolizes actual world building components such as walls, windows, doors, roofs, stairs, etc. as a 3D object. In additions to geometry details, BIM can add other data like manufacturers, fire rating, schedule, and cost estimations. BIM also can utilize the function of insert, extract, update or modify data to maintain and indicate the guidelines of stakeholders. 
BIM supports numerous advantages by improving efficiency, effectiveness, and productivity in construction industry. Some possible advantages that will supplied by implementation BIM in construction projects are (Deshmukh, 2021):

i. Agile and Efficient Communication.

ii. Model-based Construction Cost Estimation.

iii. Visualize project in Planning or Preconstruction stage.

iv. Clash Detection.

v. Enhanced Scheduling.

vi. Enhanced Productivity with Prefabrication and Modular Construction.

vii. Mitigating Risk for better safety.

viii. Organize Facility Management.

\section{Geographic Information System (GIS)}

GIS are computerized system based on cartography, remote sensing, and geography knowledge. GIS can accumulate, store, control, display, calculate analyze, and explain spatial information and data about the earth's surface and visualize abstract information (Zhang et al., 2009). GIS offer a database system with responsibility for a set of operations and spatial reference data for the detailed processing of data. For the reason of their outstanding abilities for handling spatial data, GIS can be applied for an application wide range, not only for disaster monitoring, regional planning, infrastructure maintenance and agriculture, but also for cadastral management, land surveys, environmental management, and other purposes (Zhang et al., 2009).

Furthermore, the improvement of GIS-based simulation models be able to resolve the ecological and development challenges in more precise manner. For instance, contemplating present proposals for low-carbon cities, GIS simulation models can be utilized toward assess the effect of urban designs and building types on energy performance and carbon emissions. Building simulation models may work better than real measurement, and the outcomes of the carbon emissions, energy performance analysis, and solar accessibility are accomplished to formulate standards for urban design that can be in the head to sustainable urban development (Li et al., 2016).

Different assistances of GIS to construction industry stated so far contains various areas such as cost estimate (Cheng and Yang, 2006; Bansal and Pal, 2007, Cao et al., 2015), E-commerce applications (Li et al., 2003), site layout (Cheng and O'Connor, 1996(a); Oloufa and Eltahan, 1994; Irizarry and Karan, 2012), route planning (Varghese and O'Connor, 1995; Cheng and Chang; 2001; Cheng and O'Conner, 1994(b)), visualization (Zhong et al., 2004), monitoring construction progress, and monitoring construction efficiency (Kerzner, 2003; Li et al., 2005; Cheng and Chen, 2002; Marzouk et al., 2010; Patel, et al., 2017).

In a construction project, the data such as drawing, specifications and bar charts are saved in various forms. The planner must repeatedly re-manage and translate the information stored from different sources whereas a GIS can enhance design and construction planning effectiveness by combining spatial and attribute data in a single environment (Cheng and Yang, 2001; Ebrahim, et al., 2016). 


\section{Advantages in Applying GIS in BIM for Construction Industry}

Technology of BIM and GIS offer digital display of building architectural or their environment entities, but each domain focuses on different purposes. BIM aims on detailed geometrical and semantic about building elements while GIS focused on geospatial information outside the buildings such as digital terrain modeling that assists the spatial analyses. In term of construction projects, BIM concentrates more on internal details, which emphasis on collaborating 3D graphical modeling to assist the requirements of automated drafting and attribute connecting with features, while GIS applied to utilize macro-level data like topographical maps.

Prior to that, BIM and GIS generally concentrating on their separate tasks according to their features and characteristics, but by bringing their integration, it can improve the management of construction industry because BIM and GIS can offer integrated data for building itself include their surroundings.

For example, in the development of building construction, the building normally will impact on the surrounding environment. Because of this problem, the building should be build based on the condition of surrounding environment. To create a proper building in friendly surrounding, the building structure should be examinate cautiously to build a stronger building structure. According to data supplied by GIS, it can assist in BIM applications in term of site selection, on-site layout of materials, and monitoring deliveries of construction goods, etc. Moreover, GIS also can offer benefits in term of planning such as emergency escape plan, utilities network plan, and selection of the best location for fire hosts and fire hydrant. For BIM models, it can assist to create high detailed models in GIS platform, and it can have an improvement in term of effectiveness in project management.

In order to bring the benefits between both domain (BIM and GIS), this paper prepared a method to integrate BIM and GIS by using FME platform. Data compatibility between both domains need to be clearly clarify before the process of integration can be carry out. By looking out on the data compatibility between BIM and GIS, it can bring a better practice during lifecycle construction project. Through this method, BIM data can be utilized in GIS platform.

Compatibility is a crucial degree for calculating of assisting BIM and GIS implementation in a particular perspective (Rogers, 2010), remains inspected from this perspective as it is not completely realized. Compatibility processes for developing an expertise are recognized as compatible with the values, needs, and abilities of prospective either at the organizational or user level (Karahanna, et al., 2019). Because of BIM interest stay slow down, industry and government policy makers become much more frustration. Researcher from various fields describe that a few explanations about the gradual implementation percentage of information system such as BIM and GIS are connected to the compatibility (Zuluaga and Albert, 2018; Eria and McMaster, 2017).

Now, the digital technology market does not provide an explanation of specific task for compatibility and its related practical theory of interoperability, adversely affecting demand pull and technology push (Aksenova, et al., 2018). Compatibility determines in what way BIM is supposed to be constant with the user's knowledge, requirements, and utilizing various software platforms, compatibility (at organizational and technical levels) will have to be thoroughly examined (Gourlis and Kovacic, 2016). 
Sami and Robert (2017) studied on implementation on GIS by organization in Uganda in classic diffusion pattern consistent with diffusion theory. In this study, implementation of GIS was helped by its relative advantage over, and compatibility with current technologies.

Zuluaga and Albert (2018) examine bridge case analyses in North California and discover that the Department of Transportation has implemented several fall protection additional machines that are incompatible with bridge guardrails. Therefore, they recommend that compatibility must be reviewed earlier than a fall protection system is obtained.

Wang and Dunston (2006) believe compatibility as a factor of ergonomic property. They believe that compatibility is focused wherever the virtual reality user properly illuminates interpretations of virtual and real objects. From this viewpoint, the compatibility causes developing from the variations in the format of data that is derived from virtual and real objects and impact the user's explanation of the object. It becomes the data process and model exchange time-consuming and occasionally difficult. Though, this is the general explanation in literature and can be a misunderstanding wherever a researcher explores compatibility of a latest technology.

Former experiments indicate that compatibility with the current foundation of a possibility adopter and their existing procedures or methods are most important conditions for successful of BIM implementation (Aksenova et al., 2018; Davies and Harty, 2013; Hartmann et al., 2012; Gledson and Greenwood, 2017). But this term has not been utilized accurately however somewhat as a generic term in numerous BIM application attempts. Corresponding to Rogers (2010), compatibility can be described as the extent that this technology is reliable with the needs and values, user's experience, and the existing infrastructure in a construction company.

Therefore, the doubts concerning compatibility as a crucial potential component in BIM implementation have suppressed the growth of a clear idea of the implementation procedure. To generate the integration between BIM and GIS for this construction application, the compatibility in term of their data format and data type between these two domains need to be understanding.

\section{Results}

In this session, there are three main results that will be highlighted which is the BIM modeling in Revit Architecture, BIM to GIS platform and GIS to BIM platform.

\section{BIM Modelling}

Autodesk Revit software was applied for BIM model development in this research. Autodesk Revit is a BIM software for architects, landscape architects, structural engineers, mechanical, electrical, and plumbing (MEP) engineers, designers, and contractors. The software permits customers to design a building and structure and its components in $3 \mathrm{D}$, construct the model with 2D drafting elements, and retrieve building information from the building model's database (Michael, 2012). 


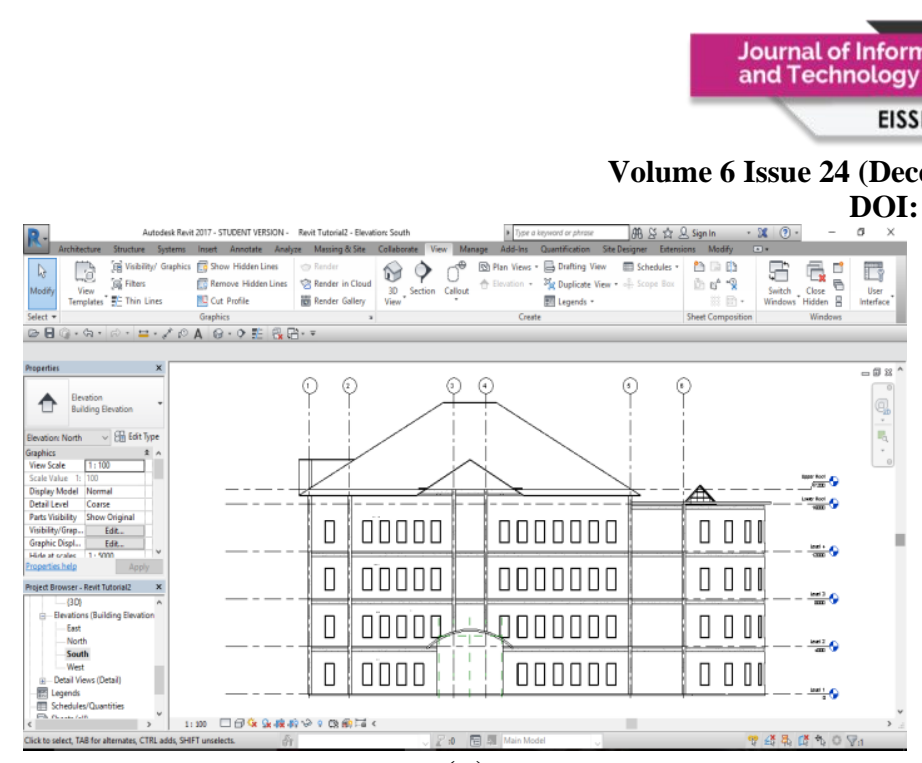

(a)

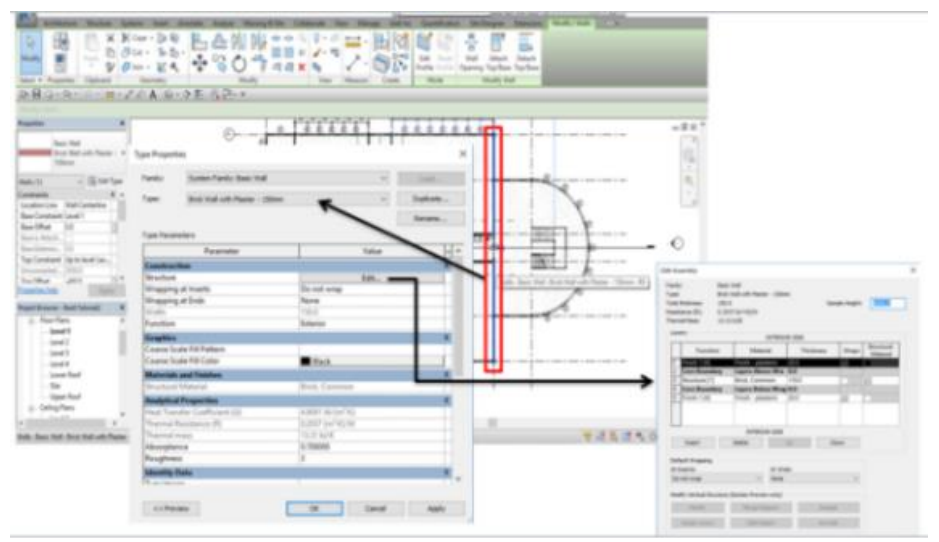

(b)

Figure 1: BIM Model in Autodesk Revit

\section{Translation from BIM to GIS Platform and GIS to BIM Platform Using FME}

Before the translation process, this study has created one data model for this purpose. This data model explanation will be discussing in another paper.

For this paper, the translation process between BIM, FME and GIS will be shown. The results from the data model that was created generate the compatibility between three domains that was used to translate all data that involve during the construction project.

For the translation data between BIM and GIS, FME was used as a data integration platform. FME (Feature Manipulation Engine) has built-in support for hundreds of formats and applications as well as transformation tools, allowing users to build and automate custom integration workflows without having to code (2021). Figure 2 below show the translation process from BIM data to GIS data using FME. 
Volume 6 Issue 24 (December 2021) PP. 278-289 DOI: 10.35631/JISTM.624026

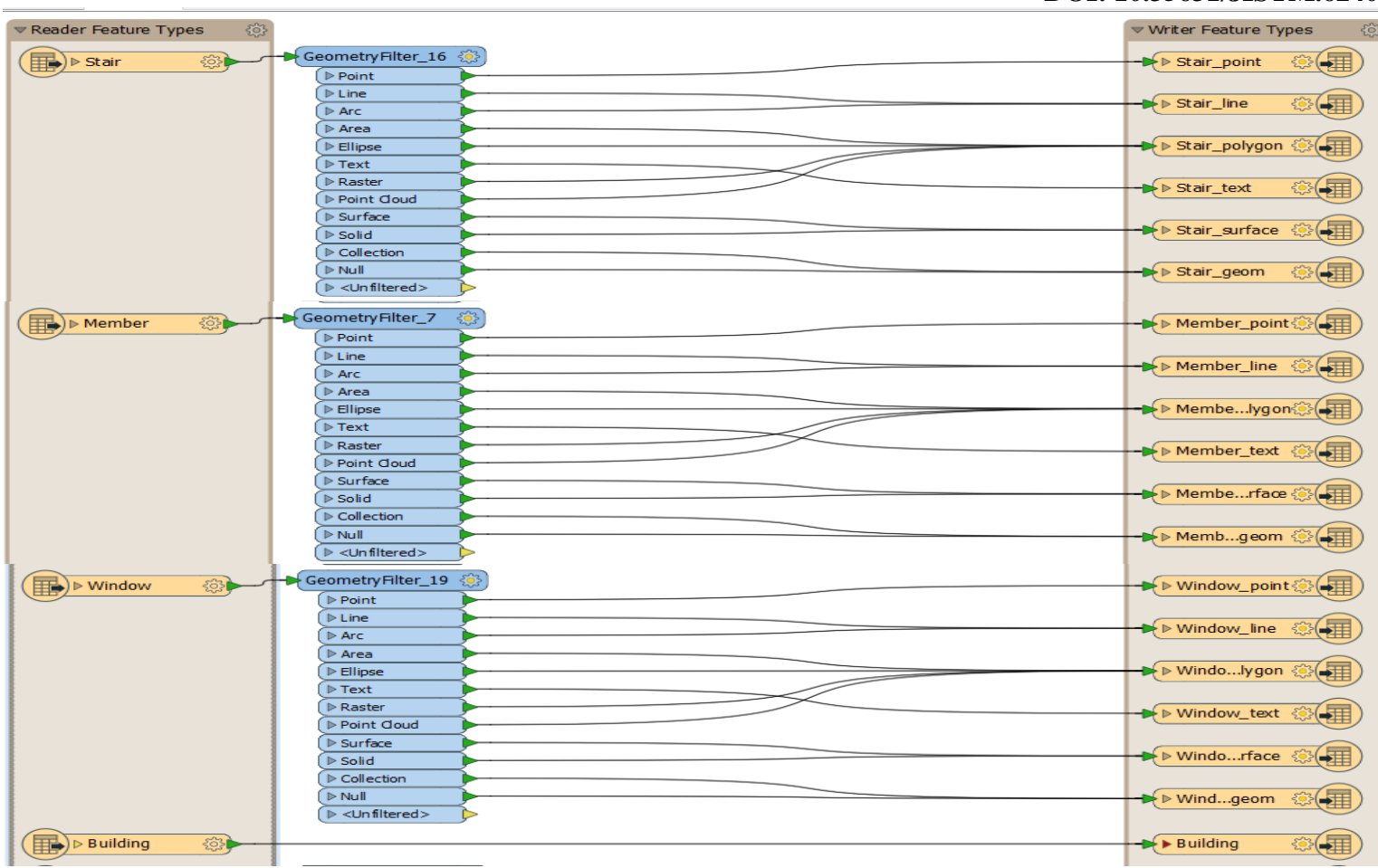

Figure 2: Example of Translation Workflow form BIM to GIS Platform

This translation includes geometric and semantic data of a single building. Figure 3 below is the results of the translation in GIS platform.

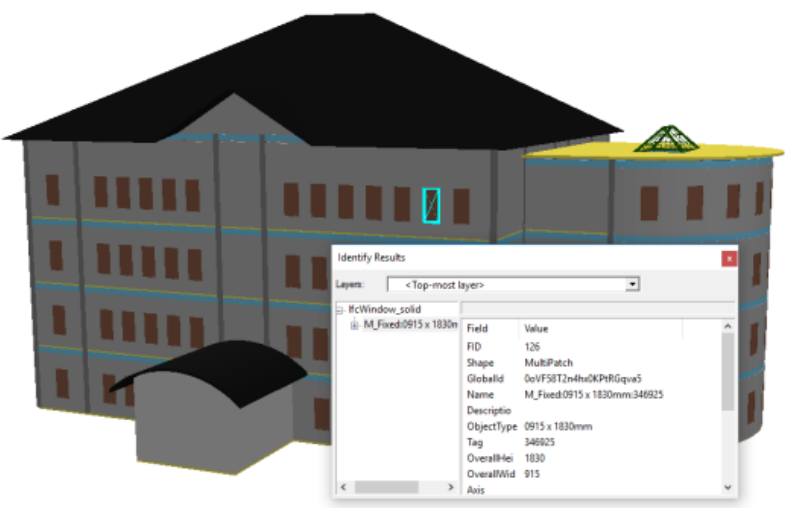

(a)

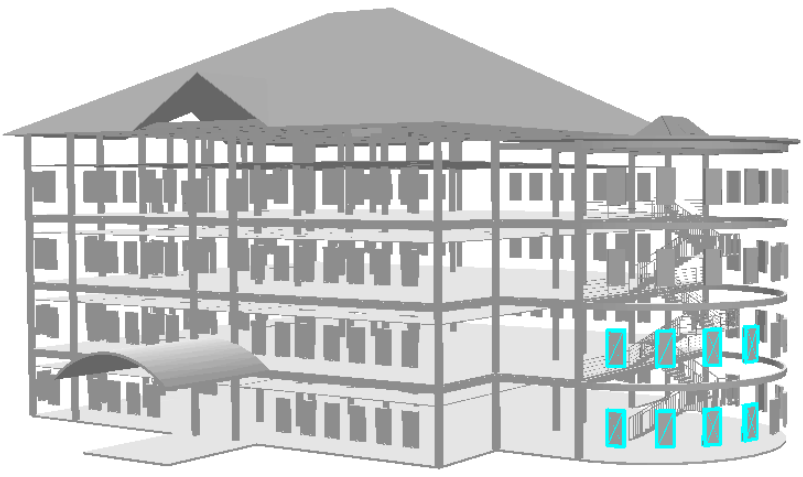




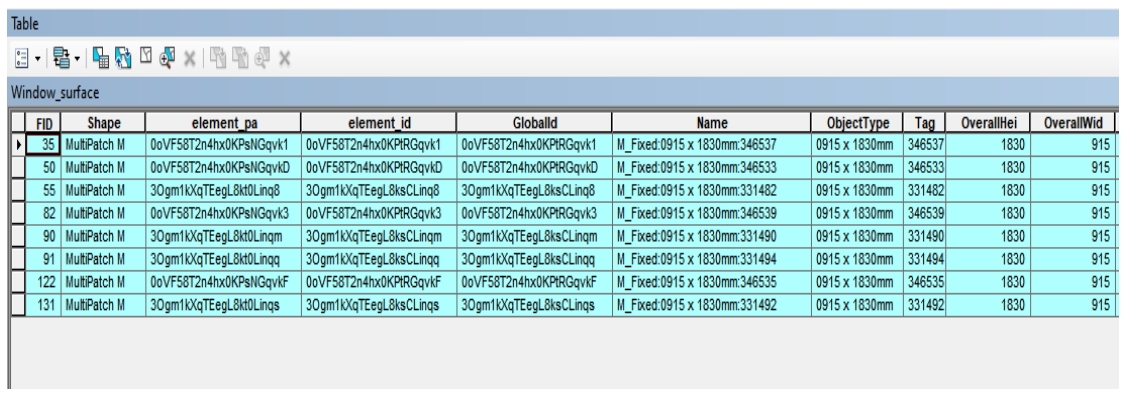

(b)

Figure 3: BIM Model in ArcGIS Platform ((A) 3D Model in ArcScene (B) The Querying Process of The Window Elements in ArcScene)

For translation GIS data into BIM data, the format use for this study is shapefile to 3D drawing (.dwg). FME platform also was used to perform the translation. During this study, results show that all the 3D geometric data were carry forward during the translation process but on the term of semantic data, there are error on part of missing data. For translation BIM into GIS, there are no missing data in terms of semantic data but for GIS into BIM, there are some semantic data missing. Because of this study is still on-going, the investigation of the semantic data missing for GIS to BIM still in progress and will discuss on difference paper. Figure 4 shows the translation process from GIS to BIM while Figure 5 shows example results of the translation GIS into 3D drawing (.dwg). After checking process, the measurement of the element (window in 3D drawing $=915 \mathrm{~mm}$; window in GIS $=915 \mathrm{~mm}$ ) is still same as the original data from GIS data (Figure 6). So, it can conclude that during the translation process there are no error in term of scaling.

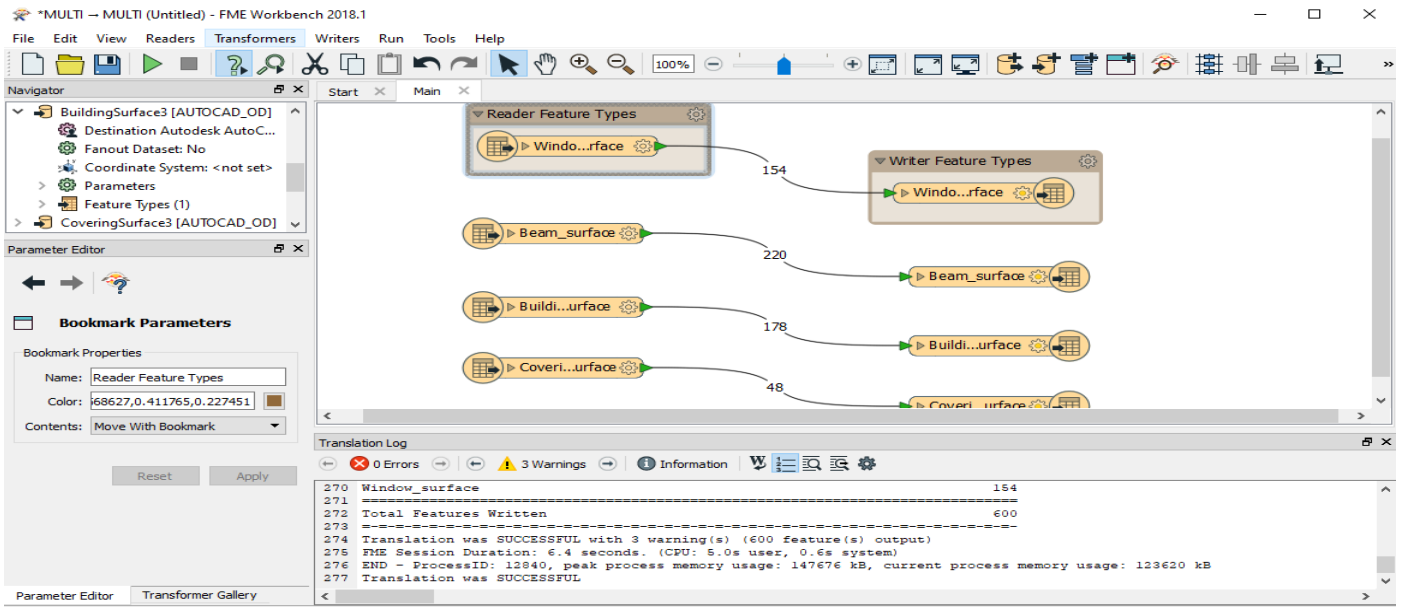

Figure 4: Translation Process from GIS to BIM 


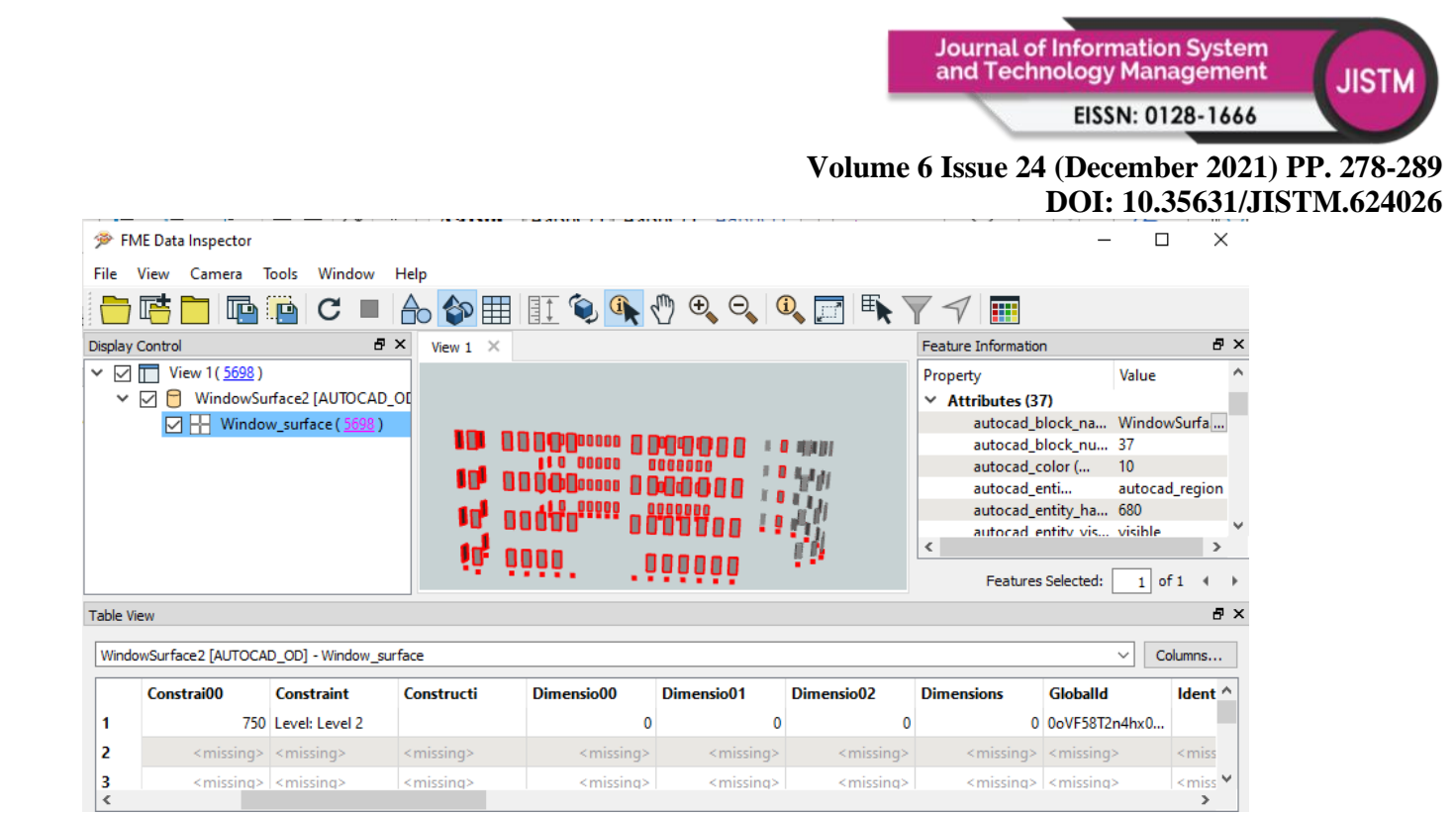

Figure 5: Some of the Translation Workflow from GIS to BIM Platform

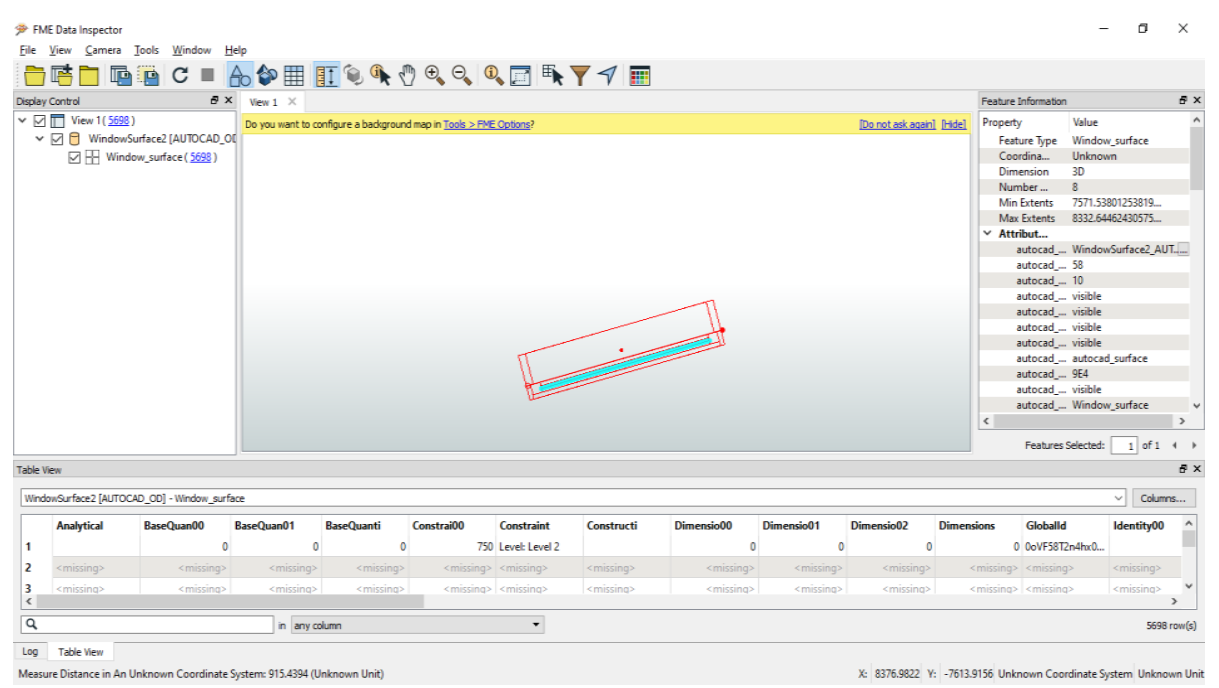

Figure 6: Measurement checking after translation process

\section{Conclusion}

This paper should be providing the initial understanding about the advantages that can GIS provides to BIM in construction industry. Besides that, this paper also can help the researcher in preparing the data exchange between BIM to GIS and GIS to BIM. Due to the differences between both domains, there are some characteristics that need to be checkup back during the translation process in order to solve the problem of semantic data missing during translation GIS into BIM.

\section{References}

Aksenova, G., Kiviniemi, A., Kocaturk, T., and Lejeune, A. (2018). From Finnish AEC knowledge ecosystem to business ecosystem: lessons learned from the national deployment of BIM. Construction Management and Economics, 37(6), 317-335.

Bansal, V.K., and Pal, Mahesh. (2007). Potential of Geographic Information System in building cost estimation and visualization. Automation in Construction, 16(3), 311-322.

Berlo L. and Laat R. (2010). Integration of BIM and GIS: The development of the cityGML geoBIM extension. Advances in 3D Geo-Information Sciences, 211-225.

Cheng, M.Y., and Yang, C.Y. (2001). GIS-based cost estimate integrated with material layout planning. Journal of Construction Engineering and Management, 127(4), 291-299. 
Cheng, M.Y., and O'Conner, J.T. (1996(a)). ArcSite: Enhanced GIS for construction site layout, Journal of Construction Engineering and Management, 122(4), 329-336.

Cheng, M.Y., and Chen, J.C. (2002). Integrating barcode and GIS for monitoring construction progress. Automation in Construction, 11, 22-33.

Cheng, M.Y., and Chang, G.L. (2001). Automating utility route design and planning through GIS. Automation in Construction, 10, 507-516.

Cheng, M.Y., and O'Conner, G.L. (1994(b)). Site layout of construction temporary facility using enhanced-Geographic Information System. Automation in Construction, 3, 1119.

Cao, D., Wang, G., Li, H., Skitmore, M., Huang, T. and Zhang, W. (2015). Practices and effectiveness of building information modelling in construction projects in China. Journal of Automation in Construction, 49, 113-122.

Davies, R. and Harty, C. (2013). Measurement and exploration of individual beliefs about the consequences of building information modelling use. Journal of Construction Management Economics, 31(11), 1110-1127.

Deshmukh, M. (2021). How does BIM benefit the Construction Industry? - Indovance Blog. Available at: http://www.indovance.com/knowledge-center/how-does-bim-benefit-theconstruction-industry/.

Eastman, C. et al. (2008). BIM Handbook: A Guide to Building Information Modeling for Owners, Managers, Designers, Engineers and Contractors. John Wiley \& Sons, Inc., Canada.

Ebrahim, M., Mosly, I., and Abed-Elrahman, I. (2016). Building Construction Information System using GIS. Arabian Journal for Science and Engineering, 41, 3827-3840.

Eria, S., and McMaster, R.B. (2017). GIS diffusion in Uganda. International Journal of Geographic Information Science, 31(5), 884-906.

Gledson, B.J., and Greenwood, D. (2017). The adoption of 4D BIM in the UK construction industry: An innovation diffusion approach, Journal of Engineering Construction Architectural Management, 24(6), 950-967.

Gourlis, G., and Kovacic, I. (2017). Building Information Modeling for analysis of energy efficient industrial buildings- A case study. Renewable and Sustainable Energy Reviews, 68(2), 953-963.

Hartmann, T., Van Meerveld, H., Vossebeld, N. and Adriaanse, A. (2012). Aligning building information model tools and construction management methods, Journal of Automation Construction, 22, 605-613.

Irizarry, J., Karan, E.P., and Jalaei, F. (2013). Integrating BIM and GIS to improve the visual monitoring of construction supply chain management. Automation in Construction, 31, 241-254.

Irizarry, J., and Karan, E.P. (2012). Optimizing location of tower cranes on construction sites through GIS and BIM integration. Journal of Information technology in Construction, 17, 351-366.

Karahanna, E., Agarwal, R., and Angst, C.M. (2006). Reconceptualizing compatibility beliefs in technology acceptance research. MIS Quarterly, 30(4), 781-804.

Kerzner, H. (2003). Project Management a System Approach to Planning Scheduling and Controlling. John Wiley \& Sons, New Jersey, Chapter 4, 511-564.

Kim, S.A., Shin, D., Choe, Y., Seibert, T., and Walz, S.P. (2012). Integrated energy monitoring and visualization system for smart green city development: Designing a spatial information integrated energy monitoring model in the context of massive data management on a web-based platform. Automation in Construction, 22, 51-59. 
Kocakaya, M.N., Namli, E., and Isikdag, U. (2019). Building Information Management (BIM), A new approach to project management. Journal of Sustainable Construction Materials and Technologies, 4(1), 323-332.

Kubba, S. (2012). Handbook of Green Building Design and Construction - Building Information Modeling. (Butterworth-Heinemann), 201-226.

Li, Z., Quan, S.J., and Yang, P.J. (2016). Energy performance simulation for planning a low carbon neighborhood urban district: A case study in the city of Macau. Habitat International, 53, 206-214.

Li, H., Kong, C.W., Pang, Y.C., Shi, W.Z., and Yu, L. (2003). Internet-based geographic information system for E-commerce application in construction material procurement, Journal of Construction Management, 129(6), 689-697.

Li, H., Chen, Z., Yong, L., and Kong, S.C.W. (2005). Application of integrated GPS and GIS technology for reducing construction waste and improving construction efficiency. Automation in Construction, 14, 323-331.

Marzouk, M., Hisham, M., Ismail, S., Youssef, M. and Seif, O. (2010). On the use of building information modeling in infrastructure bridges. Proceedings of the 27th International Conference - Applications of IT in the AEC Industry (CIB W78), 1-10.

Micheal, G. (2012). Architecture and The Lost Art of Drawing. The New York Times. Available at: https://www.nytimes.com/2012/09/02/opinion/sunday/architecture-andthe-lost-art-of-drawing.html.

Oloufa, A.R., Eltahan, A.A., and Papacostas, C.S. (1994). Integrated GIS for construction site investigation. Journal of Construction Engineering and Management, 120(1), 211-222.

Patel, K.M., Patel, T., and Patel, P.J. (2017). Application of GIS in Construction Management. International Conference on Construction, Real Estate, Infrastructure and Project Management, 104-112.

Penttilä, H. (2006). Describing the changes in architectural information technology to understand design complexity and free-form architectural expression. ITCON 11 (Special Issue the Effects of CAD on Building Form and Design Quality), 395-408.

Rogers, E.M. (2010). Diffusions of Innovation. Simon \& Schuster Inc., New York, 224-234.

Sacks, R. et al. (2010). The Rosewood experiment - Building information modeling and interoperability for architectural precast facades. Automation in Construction, 19(4), 419-432.

Safe Software. (2021). FME - Data Integration Platform. Available at: https://www.safe.com/fme/.

Varghese, K., and O'Conner, J.T. (1995). Routing large vehicles on industrial construction site. Journal of Construction Engineering and Management, 122(1), 1-12.

Wang, W., and Dunston, P.S. (2006). Compatibility issues in Augmented Reality systems for AEC: An experimental prototype study. Journal of Automation Construction, 15(3), 314-326.

Yuan, Y. and Shen, Q.P. (2010). Using IFC standard to integrate BIM models and GIS. In: Proceedings of 2010 International Conference on Construction and Real Estate, 1-2 Dec, Brisbane, Australia, 224-229.

Zhang, X., Arayici, Y., Wu, S., Abbott, C., and Aouad, G. (2009). Integrating Building Information Modeling and Geographic Information System for large-scale facilities asset management: A critical review. In: B.H.V. Topping, L.F. Costa Neves, R.C. Barros (Eds.). Proceedings of the Twelfth International Conference on Civil, Structural and Environmental Engineering Computing, Civil-Comp Press, Stirlingshire, UK. 
Volume 6 Issue 24 (December 2021) PP. 278-289 DOI: 10.35631/JISTM.624026

Zhong, D., Li, J., Zhu, H., and Song, L. (2004). Geographic Information System based visual simulation methodology and its application in concrete dam construction process. Journal of Construction Engineering and Management, 130(5), 724-750.

Zuluage, C.M., and Albert, A. (2018). Preventing falls: Choosing compatible Fall Protection Supplementary Devices (FPSD) for bridge maintenance work using virtual prototype. Safety Science, 108, 238-247. 